\title{
RAPD Fingerprinting and Genetic Relationships of Some Wheat Genotypes
}

\author{
Manal Eid \\ Botany Department, Faculty of Agriculture, Suez Canal University, Ismailia, Egypt \\ Email address: \\ eid_manl@hotmail.com \\ To cite this article: \\ Manal Eid. RAPD Fingerprinting and Genetic Relationships of Some Wheat Genotypes. International Journal of Genetics and Genomics. \\ Vol. 7, No. 1, 2019, pp. 1-11. doi: 10.11648/j.ijgg.20190701.11
}

Received: December 14, 2018; Accepted: January 15, 2019; Published: February 4, 2019

\begin{abstract}
The genetic variability and relationships among 5 Egyptian wheat genotypes representing Sakha8, Sakha69, Sakha93, Sids1 and Gemmiza7 were analyzed using 8 random amplified polymorphic DNA (RAPD). A total of 77 loci (73 \% polymorphic) in all 5 wheat genotypes was amplified and discriminated all the wheat genotypes. PIC, RP, MI, DP values were evaluated and revealed degree of genetic divergence among the cultivars used. A cluster based on UPGMA (Un-weighted PairGroup Method with Arithmetic Mean) analysis was used to determine genetic similarities. The five wheat genotypes were divided into two main clusters. Cluster 1 was divided into two groups. In subgroup 1 were included genotype 1 and genotype 2. They seemed very close which might depict sharing of the genetic background among the genotypes. In consequence, the close genetic relationships are entirely alarming and may hinder further plant improvement. Genotype 5 was in subgroup 2. The second cluster was included genotype 3 and genotype 4. The same genotypes were also assessed in field conditions for structural analyses, which were carried out based on six yield components. The dendrogram created was comparatively analyzed with the RAPD dendrogram. This study additionally indicates that RAPD markers are useful for distinguishing and characterizing wheat cultivars. The genetic relatedness among these genotypes could provide useful information for conservation and selection of cross parents in breeding.
\end{abstract}

Keywords: Wheat, RAPD, Polymorphic, Genetic Relatedness, Clusters

\section{Introduction}

Wheat (Triticum aestivum L.) is one of the most important and widely cultivated crops in the world, used mainly for human consumption and support nearly $35 \%$ of the world population. The total cultivated area of wheat is more than 200 million hectares and total wheat production is about 733 million tons per year [1]. By 2020, the world demand for wheat is expected to be $40 \%$ higher than that of its level in the latter half of the 1990s [2]. Wheat is a member of the family Poaceae, which includes major cereal crops such as sorghum, maize, wheat, rice, millet and barely [3]. Wheat is self-pollinated, hexaploid crop which having $2 n=6 x=42$ chromosome. The hexaploid wheat have large genome size (approximately $17,000 \mathrm{Mb}$ ), a high proportion of repetitive DNAs, continuous inbreeding caused by self-pollination and a narrow genetic base represent the difficulties for use of molecular markers [4].

Nowadays in Egypt there is an urgent need to increase the productivity level of wheat to reduce the food gap resulting from population increase. The annual Consumption of wheat grains in Egypt is about 12.4 million tons, while the annual local production is about 8.52 million tons / 1.32 million hectare in 2013/2014 [5]. Because of wheat is a staple food, it occupies an important place in the crop husbandry of Egypt. Although wheat production in Egypt has been better during recent years than it was previously, continued improvement in productivity is highly desirable because of increasing demand by the still-growing human population. However, during the last few years, yield improvement in wheat varieties has not been substantial; the narrow genetic base of the germplasm in use has been considered the main reason. Knowledge of genetic diversity and gene action of various wheat traits is useful in making decision with regard to appropriate breeding system effects were played the major role in controlling the genetic variation in the days to flowering, one thousand grain weight and grain yield per plant and allows plant breeders to better understand the 
evolutionary relationships among accessions, to sample germplasm in a more methodical way, and to develop strategies to merge useful diversity in their breeding programs [6].

However, Breeding programs are continually developing new cultivars with specific genotypic and phenotypic requirements. The development, validation, optimization and implementation of markers can assist in this process, as well as the maintenance of genetic variation and the protection of plant breeder's rights [7]. Phenotypic or morphological markers are the oldest descriptors used to differentiate one cultivar from another [8]. These markers represent the first methods used in the taxonomic and agronomic classification of crop germplasm [9].

Despite the role played by phenotypic markers in cultivar development, it faces many challenges. Their limited numbers and their greater dependency on both environment and growth stage of the plant for observation hinder the application of phenotypic markers in the differentiation of germplasm. Epistatic and pleiotropic gene effects also limit the efficiency of phenotypic markers as a reliable differentiation tool [10]. It is really difficult for the wheat breeders to develop physical marker with other good agronomic characters and they think to do backcrosses to solve these problems, which is also time consuming and sometimes did not find any positive results. DNA finger printing might be a good solution to overcome this problem. Molecular markers are a useful complement to morphological and physiological characterization of cultivars because they are plentiful, independent of plant tissue or environmental effects, and allow cultivar identification very early in plant development [11]. Molecular markers are the molecules that could be used to trace a desired gene (s) in test genotypes. In fact, a piece of DNA or a protein can be used as a marker. Earlier approaches that made selection of specific traits easier were based on the evolution of morphological traits [12-14]. However, DNA markers seem to be the best candidates for efficient evaluation and selection of plant material. Unlike protein markers, DNA markers segregate as single gene and they are not affected by the environment. Recently the concept of marker-aided selection had provided an advantage of molecular marker-based approaches for crop improvement as compared to selection based solely on phenotype [15-19].

Molecular characterization of cultivars is also useful to evaluate potential genetic erosion, i.e., a reduction of genetic diversity along the breeding process. DNA-based markers are particularly useful in wheat and other crops with an apparent narrow genetic background.

RAPD (Random Amplified Polymorphic DNA) markers are frequently using for DNA finger printing since 1995. The whole protocols might be used for the future developed wheat lines, so the complication of identifying characters of new lines will be eliminated. Molecular markers have provided a powerful approach to analyze genetic relationships among accessions in many crop species. A RAPD marker involves the amplification of genomic DNA with single primers of an arbitrary nucleotide sequence [20]. This single primer binds genomic DNA at the two opposite sites of the different strands of the template DNA [21].

DNA polymorphisms are generated, because of the nucleotide base changes in the primer binding sites or insertion and deletion within amplified sites as detected by the presence or absence of amplified products [22]. RAPDs have been used as genetic markers for the identification of cultivars, fingerprinting of genomes, evaluation and characterization of genotypes in many crop species [23]. RAPD technique has been successfully used for the assessment of genetic diversity in wheat [24-25].

Since wheat is characterized by a large genome and little or no sequence information is available for the wheat genome. This study was made a RAPD analysis of five genotypes of wheat to estimate their genetic diversity and relatedness; to develop genotype specific molecular fingerprints through identifying unique DNA markers. In addition to assess phenotypic variability according to six agronomical traits; the information gathered will be helpful for our breeding programs.

\section{Material and Methods}

Field experiments were conducted at the Experimental Farm, Faculty of Agriculture Suez Canal University, Ismailia, Egypt during 2016/2017. The experimental material comprised five cultivars of wheat namely, Sakha8, Sakha69, Sakha 93, Sids1 and Gemmiza7 (Table1). Grain samples were obtained from Field Crops Research Institute, Agriculture Research Center, Giza, Egypt. The experimental design used randomized complete block design (RCBD) with three replicates. The experimental plot consisted of 6 rows, 3 $\mathrm{m}$ long and $5 \mathrm{~cm}$ apart in which grains were drilled by hand. The normal recommended agricultural practices of wheat production were applied at the proper time.

\subsection{Agronomical Traits}

The central three rows were used for measurements to avoid border effects. Ten random plants from each plot were selected and the different traits were measured. The plants in $1 \mathrm{~m} 2$ in each plot were harvested to calculate yield and yield components. At physiological maturity, plant height was measured from the soil surface to the top of the spike on the main shoot. Spike length of the main spike of the selected plant excluding awn was measured in centimeters, number of spikes per plant. Number of grains per spike was counted from the spikes used for measuring spike length. The total number of grains recorded was divided by the number of spikes, and the average was computed. For 1000 grainweight, a single sample of 1000 grains was counted in grams from the yield of the selected plants.

Statistical analysis

Quantitative analyses of morpho-agronomic traits carried out using SAS [26] software and SPSS 16.0 (cluster analysis based on Euclidean distance square). 


\subsection{DNA Extraction}

\section{Plant collection}

Young, vigorously growing fresh leaf samples from five wheat cultivars were collected from 21 days old seedlings to extract genomic DNA. Initially, healthy portion of the youngest leaf of the tiller were cut apart with sterilized scissors and washed in distilled water and ethanol and dried on fresh tissue paper to remove spore of microorganisms and any other sources of foreign DNA. The collected leaf samples (Ten samples for each cultivar) were then kept in polythene bags and for avoiding any damage of the leaf tissues the bags were placed in an ice box to carry it in Lab. and finally, the samples were stored in $-80^{\circ} \mathrm{C}$ freezer.

DNA isolation

The basic DNA extraction protocol using the CTAB (cetylhexadecyl-trimethyl ammonium bromide) method described by Dellaporta et al. [27] was used with slight modifications by Porebski et al. [28], for obtaining good quality total DNA. A weight $(0.2 \mathrm{~g})$ from young leaves were ground in liquid nitrogen to fine powder and extracted using $10 \mathrm{ml}$ preheated $\left(65^{\circ} \mathrm{C}\right)$ cetylhexadecyl-trimethyl ammonium bromide (CTAB) extraction buffer [3\% CTAB (w/v), 100 mMTris- HCl, pH 8.0, 20 mM EDTA, 1.4 M NaCl, 2\% (w/v) PVP (Polyvinyl pyrrolidone)], then $1 \%(\mathrm{v} / \mathrm{v})$ of $\beta$ mercaptoethanol $(15 \mathrm{mM})$ with further grinding. The mixture was incubated at $65^{\circ} \mathrm{C}$ for $60 \mathrm{~min}$, followed by two extractions with chloroform/isoamyl alcohol (24:1). The nucleic acids were precipitated with cold isopropanol, and the pellet was dissolved in $1 \mathrm{~mL}$ TE $0.1 \mathrm{X}$ (Tris-EDTA) buffer (10 mMTris- $\mathrm{HCl}, \mathrm{pH}=8$ and $1 \mathrm{mM}$ EDTA, $\mathrm{pH}=8)$. Coprecipitated RNA was removed by digestion with RNAase A. $4 \mu \mathrm{l}(10 \mathrm{mg} / \mathrm{mL})$. The DNA was further purified by $300 \mu \mathrm{l}$ phenol: chloroform: isoamyl alcohol $(25: 24: 1)$, then left overnight at $\left(-20^{\circ} \mathrm{C}\right)$ using $1 / 10$ vol. from $2 \mathrm{M}$ sodium acetate $(\mathrm{pH}=8.0)$ and one volume of cold isopropanol alcohol. The precipitate was washed twice with $10 \mathrm{mM}$ ammonium acetate in $76 \%$ ethanol, and the pellet was dissolved in 0.1 XTE buffer. The purified total DNA was quantified by gel electrophoresis, and its quality verified by Nano drop spectrophotometer model ND1000. DNA samples were then stored at $4^{\circ} \mathrm{C}$. DNA samples of each cultivar were analyzed individually to detect intra-cultivar variations and bulked to detect inter-cultivar variations.

\subsection{PCR Based Amplification with RAPD Primers}

RAPD Analysis was performed with were selected from
Operon Technology, USA (Table2). DNA from each cultivar used to amplify with universal primer each contain in a volume of (final concentration) dNTPs $(10 \mathrm{mM})$, PCR assay buffer (10 X), $\operatorname{Mgcl} 2(25 \mathrm{mM})$, primers (5 p mol ), Taq DNA polymerase ( $3 \mathrm{U} / \mu \mathrm{l})$, DNA ( $60 \mathrm{ng}$ ) and sterile water to make the volume The reaction was carried out in thermo cycler using an initial cycle of denaturation at $94^{\circ} \mathrm{C}$ per 2 min. Second denaturation at $94 \mathrm{oC}$ at $30 \mathrm{sec}$ annealing at $37 \mathrm{oC}$ for 30 seconds extension for 5 minutes at $72^{\circ} \mathrm{C}$. and final extension at $72^{\circ} \mathrm{C}$ with 35 cycles repeats. The fragments obtained and analysis was carried out. The molecular weight marker gene ruler $100 \mathrm{bp}$ DNA ladder was used as a standard and to determine the size of polymorphic fragments. After electrophoresis, gel was visualized under UV transillumination and was photographed using gel doc system. DNA fragment was done using inbuilt software and by scoring photographs. Individual bands with lanes were assigned to a particular molecular weight comparing with DNA molecular weight marker. Total number of bands within each; lanes and number of polymorphic bands were noted.

\subsection{Data Scoring and Analysis}

RAPD amplified bands were scored as present (1) and absent (0) for each primer population combination. The data entry was in a binary data matrix as discrete variable with Jaccards coefficient similarity was calculated and dendrogram was generated based on similarity coefficient by using paired group method. Most efficient primers were selected on the extent of polymorphism. The scores obtained using all polymorphic markers in the RAPD analysis were then calculated for number of alleles, effective number of alleles. Power Marker version 3.25 was used to determine the polymorphism information content (PIC) [29]. Genetic diversity was calculated using Simpson's information index and Shannon's diversity index [30]. Efficiency of polymorphism detection as the Marker index (MI) and Effective multiplex ratio, defined by Powell et al. [31]. The resolving capacity of primers (Rp) was determined according to Prevost \& Wilkinson [32] as $\mathrm{Rp}=\Sigma \mathrm{Ib}$, where $\mathrm{Ib}$ (band informativeness $)=1-(2 \times|0.5-p|)$, and $\mathrm{p}$ is the proportion of genotypes in samples containing the band. The discrimination power (D) is an estimation of the probability that two randomly sampled accessions could be distinguished by their RAPD profiles [33]. This parameter was calculated as $\mathrm{D}=1-\mathrm{C}$, where $\mathrm{C}$ is the probability of coincidence, $(\mathrm{C}$ $=\Sigma p_{i}^{2}$, where $p_{i}$ being the frequency of different genotypes for a given locus).

Table 1. Pedigree and the origin of five wheat genotypes.

\begin{tabular}{llll}
\hline Number & genotype & Pedigree & Origin \\
\hline 1 & Sakha8 & Indus/Norteno "s" & Egypt \\
2 & Sakha69 & INIA/RL4220//7C/YR"s"CM15430-2S-1S-0S & Egypt \\
3 & Sakha93 & Sakha 92/TR 810328 & Egypt \\
4 & Sids1 & HD2172/PAVON"s"//1158-57/MAGA74"s" & Egypt \\
5 & Gemmiza7 & 7CMH74A-630/SX//SERI82/AGENT & Egypt \\
\hline
\end{tabular}


Table 2. Codes and sequence for 8 Arbitrary Random 10-mer Primers for RAPD amplification.

\begin{tabular}{lllll}
\hline number & Primer code & Primer Sequence & number & Primer code \\
\hline 1 & OPT-08 & 5-AACGGCGACA-3 & 5 & OPW-04 \\
2 & OP-B07 & 5-GGTGACGCAG- & 6 & OPN-10 \\
3 & OP-B3 & 5-CATCCCCCTG-3 & 7 & OP-B12 \\
4 & OPN-06 & 5-GAGACGCACA-3 & 8 & OPC-ACAACTGGGG-3 \\
\hline
\end{tabular}

\section{Results and Dissection}

\subsection{Variation in Agronomic Characteristics of the Five Genotypes of Wheat}

Agronomical and phenological traits are among the first phenotypic markers used in germplasm management. Although, they have a number of limitations including low heritability, late expression and vulnerability to environmental influences [34]. They are very important for grouping wheat genetic resources, and also are essential and useful for plant breeders seeking to improve existing germplasm by introducing novel genetic variation for certain traits into the breeding populations [35-37]. Therefore, these characteristics have good potential in order to select and to conserve genotypes. In this study, the results of analysis of 5 quantitative traits used indicated this type of markers well suited to estimate differences between 5 wheat genotypes.

Plant height: It is a crucial factor for understanding the development of plant. Plant height was recorded in $\mathrm{cm}$. in all the genotypes at the time of maturity (Table 3 ). Variation in plant height was observed in different wheat genotypes and varied from $45.1 \mathrm{~cm}$ in Sakha8 and Sids1 to $107.3 \mathrm{~cm}$ in Sakha93 with an average value of $72.1 \mathrm{~cm}$.

Length of spike: The length of spike is directly contributed to yield component and is a character of considerable importance, as the larger spike is likely to produce more grains and eventually higher yields per plants [38-39]. The result showed that the length of spike varied from $8.1 \mathrm{~cm}$ in Sakha 8 to $17.0 \mathrm{~cm}$ in Sakha 93 with an average value of 11.9 $\mathrm{cm}$. Moreover, Sakha93 retaining larger spikes compared with other 4 cultivars in this study is recommended to be more productive under any environment.

Number of spikes /plant: This parameter is also directly related to plant yield. The no. of spikes per plant varies from 1.5 in Sids1 to 17.3 in Sakha93 with an average of value 5.5.

Number of grains per spike: grains per spike is direct measure of yield/plant and also economically important. It varies from genotype to genotype as shown in Table 3 . The maximum grains /spike observed in Sakha93i.e. 32.0. On the other hand, the minimum number of grains were observed in Gemmiza7 i.e. 13.5 with an average value of 20.5. The results of number of spikes per plant and number of grains per spike for Sakha93 cultivar are constant with the results of Abou-Deif et al. [40].

Heading date: One of the most important traits in wheat is heading date to the target environment and life cycle duration that will help maximize yield potential in any environment [41-42]. The data showed that Gimmeza7 was the earliest one of heading date in 89.3 days followed by Sakha93, Sakha8, Sids1 and Sakha69 in 92.0, 94.2, 95.0 and 100.8 day. Contrast to results by Abdelsalam and Reham [43] who recorded that Sakha93 cultivar was as the earliest one of heading date in average 50.32 days, followed by Sids1 cultivar in average 61.30 days. Also, Al-Naggar et al. [44] recorded that heading date in average 95 day for Sakha93 Cultivar. According to Kiseleva et al. [45] who proposed that the probable cause of heading date differences may be due to differences in the origin of interacting heading time pathways and putative transcription factors located on 5B chromosome might modulate. Up to this point, it is needed to expand further investigation of the transcription factors and their hypothetic interaction with known heading date genes could help to further decipher the heading time pathways in wheat.

Thousand Grain weight: The actual yield of the genotype is measured by thousand grain weight as the yield of plant depends upon size as well as weight of seeds of genotype. In Table 3 tested weight of the grain varies from $22.3 \mathrm{gm}$ in Gimmeza7 to $50.0 \mathrm{gm}$ in Sakha93 with an average of value $31.4 \mathrm{gm}$.

Among the agronomic and morphologic traits, selecting genotypes using 1000-seed weight, number of grains per spike was improved yield. Due great benefits from selection might be expected for all the traits studied in Sakha93. These results were in accordance with the findings of Ahmadizade et al. [46]; Talebi and Fayyaz [47].

For yield components, indicated by the value of by the value of coefficient of variation (Table 3 ), the highest variations were detected for number of spikes with1.23. While the lowest value (0.04) was in heading day trait.

Shannon Diversity index was used, as a measure of phenotypic diversity of each trait (Table 3). Heading day showed the highest variation (1.61) among all qualitative traits, followed by plant height and spike length. No of spike showed the lowest variation (1.12). Average Shannon genetic diversity index was 1.5 . These results are in accordance with Nimbalkar et al. [48] and Shashikala [49].

Genetic similarity was calculated for five genotypes (data not shown). The similarities varied from 0.05 (genotype 3 vs. genotype 4) to 0.99 (genotype1 vs. genotype 4).

A dendrogram based on UPGMA analysis with Agronomical and phenological data (similarity matrix) was illustrated in Figure1. The five wheat genotypes were divided into two main clusters. Sakha93 separated from the other four genotypes. The second cluster was divided into two groups. In subgroup 1 were included 1, 4, 5 genotypes whereas genotype 1 and genotype 4 were the closet. Genotype 5 was in subgroup 2. 
Table 3. Agronomical observations of wheat genotypes.

\begin{tabular}{lllllll}
\hline Genotypes & Plant height & Spike length & No. Spike & No. grain/spike & Heading days & 1000 grain weight \\
\hline Sakha8 & 45.1 & 8.1 & 2.2 & 17.0 & 94.2 & 24.2 \\
Sakha69 & 82.0 & 14.4 & 4.3 & 25.6 & 100.8 & 36.3 \\
Sakha93 & 107.3 & 17.0 & 17.3 & 32 & 92.0 & 50.0 \\
Sids1 & 45.1 & 9.7 & 1.5 & 14.3 & 95.0 & 24.3 \\
Gemmiza7 & 81.0 & 10.2 & 2 & 13.5 & 89.3 & 22.3 \\
Total & 360.5 & 59.4 & 27.3 & 102.4 & 471.3 & 157.1 \\
Mean & 72.1 & 11.9 & 5.5 & 20.5 & 94.3 & 31.4 \\
Coefficient variation (CV) & 0.37 & 0.31 & 1.23 & 0.39 & 0.04 & 0.37 \\
Standard division (SD) & 26.7 & 59.5 & 6.7 & 8.03 & 4.3 & 15.9 \\
Shannon index & 1.57 & 1.57 & 1.12 & 1.56 & 1.61 & 1.56 \\
\hline
\end{tabular}

\begin{tabular}{|c|c|c|c|c|c|c|}
\hline$C A S E$ & & 5 & 10 & 15 & 20 & 25 \\
\hline Label & Num & +-- & & & --+- & --+ \\
\hline G1 & 1 & & & & & \\
\hline G4 & 4 & لـ & & & & \\
\hline G5 & 5 & $-\longrightarrow$ & & & & \\
\hline G2 & 2 & - & & & & \\
\hline G3 & 3 & - & & & & 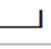 \\
\hline
\end{tabular}

Figure 1. Dendrogram for the five wheat genotypes constructed from agronomical data using (UPGMA), Genotype codes: see Table 1.

\subsection{RAPD Polymorphism}

Eight primers with ten base arbitrary were amplifying the genomic DNA of 5 wheat genotypes, produced 77 loci. The total no. of DNA bands amplified varied between 4 and 18 with the average of 9.6 bands per primer. The primer $\mathrm{P} 3$ gave the highest number of bands (18), while the P7 primers yielded the lowest number of bands (4). The primer produced higher number of bands could have better application to find out the polymorphisms in heritability of wheat cultivars. It has been shown that increasing the number of alleles, indicating a greater magnitude of diversity among the plant materials included in this investigation. The level of variation depicted by number of bands at each primer serves as a measure of genetic variability having direct effect on differentiation of cultivars within a species. High mean number of observed alleles (allelic diversity) per primer displayed high genetic variation and indicates that the population is under mutation drift equilibrium [50].

Total percentage of polymorphism for all primers used was $73 \%$. This amply suggested that the genotypes selected for this study harbor enough genetic divergence. This value of polymorphism is constant partially with Ramiz et al. [51].

Out of 77 loci scored, the 21 were monomorphic- identical for all analyzed genotypes, may indicate that the primer has annealing sites at the same position of all genotypes genomes and/ or may be attributed to the amplification of highly conserved regions in the genome that make amplification bands similar to each other in molecular weight (monomorphic) [52].

The percentage of polymorphic bands obtained for each primer did not correlate to the total number of bands. For instance, the total number of bands scored for primerl and primer 2 was relatively high, 8 and 13, respectively, with $50 \%$ and $54 \%$ of them being polymorphic. In contrast, the lowest number of total bands was obtained for primer 5 and primer7, and both of these were polymorphic (100\%) (Table 4). The high polymorphism revealed by molecular markers/primers is hinged on the present of repeat sequences $\mathrm{AC}, \mathrm{CA}, \mathrm{AG}$ and GA. It can be observed that the primers that gave $100 \%$ polymorphism had the repeated sequences as reported by Ajibade et al. [53] and corroborated by Ghalmi et al. [54]. It might probability be that the ability to resolve genetic variation in any crop species is more directly related to the number of polymorphism detected by the marker techniques as well as the percentage of polymorphic RAPD.

However, the total number of the amplified DNA products (bands) yielded 237 using 8 primers. Also, a noticeable variation present between the cultivars in the number of bands as listed in Table 5, Gemmiza7 recorded the highest number of bands (62), while Sakha93 recorded the lowest number of bands (34). The variation in polymorphism among the primers in one cultivar or the all primers in one cultivar may be attributed to several causes such as, the loss or alteration (deletion or insertion) of one or both of the opposed pair of primer binding sites needed to produce the PCR product. Or as a result of nucleotide changes (e.g. point mutation) at the primer annealing site in genome DNA that prevents amplification by introducing a mismatch at just one end of a DNA segment then the DNA polymorphism observed by RAPD results. Alternatively, an insertion between the primer annealing sites may place them at different distances (lengths) or even too great to allow the amplification products [55].

Effective number of alleles $(\mathrm{Ne})$ was less than the observed values ranging from 3.62 (primer 7) to 14.29 (primer 3) with mean of 7.9. The effective number of alleles is estimator of usefulness of RAPD for cultivar distinction [56-57].

Polymorphism information content (PIC): Polymorphism information content is the probability of detection of polymorphism by a primer/primer combination between two 
randomly drawn genotypes and depends on the number of detectable alleles and the distribution of their frequency. Because of the high credibility of the PIC index, this parameter has been used widely in numerous genetic diversity researches [58-61].

The average of PIC values for the eight primers was 0.85 and ranged from 0.72 to 0.93 (Table 4). The lowest PIC value (0.72) was recorded for primer7 whereas the highest value (0.93) was in Primer 3. Lower PIC value may be the result of closely related genotypes and higher PIC values might be the result of diverse genotypes.

Seventy five percent of the primers ( 6 primers) had PIC values above 0.85 indicating that these primers are highly informative for determining wheat genotypes polymorphism. According to Botstein et al. [62] reported that molecular markers have PIC values higher than 0.5 are considered highly informative. These high estimates of PIC substantiated the suitability of used set of DNA markers to applications such as linkage-mapping programs in addition, to genetic polymorphism studies in other wheat cultivars breeding too. In this the result, the PIC values were found to be higher than that of Najaphy et al. [58]. It could be attributed to the diverse nature of the five wheat genotypes and/or highly informative eight RAPD markers used.

The highest value of Shannon index was observed in P3 primer (2.77), while the lowest value occurred in P7 primer (1.34) with average value of 2.05. The same degree of genetic heterogeneity was discerned through Simpson's information index. These results are higher than those of Bibi et al. [63] that measured Shannon's index value ranged from 0.38 to 0.57 , with an average of 0.49 . it might be due to different materials and different primers. However, it was noticed that the primer with the highest value of genetic diversity of Shannon and Simpson indexes also had the highest number of polymorphic bands and the opposite was true. P3 primer had the highest values of polymorphic bands and the values of Shannon and Simpson indexes while the P7 primer had the lowest values for these parameters. Therefore, P3 primer looks optimal marker for characterization the wheat varieties.

Marker Index (MI) and Effective multiplex ratio (EMR): MI is a feature of a marker and was calculated for all eight primers. High MI values were scored with primers primer 3 (1.63), primer $6(1.11)$. The lowest MI scores were obtained with primers $7(0.36)$, primer $1(0.44)$ and primer $5(0.47)$. These primers amplified low number of PCR products. The effective multiplex ratio (EMR) is the number of polymorphic fragments detected per primer. EMR values varied from 0.50 to 1.76 with a mean value of 0.88 . Primer 3 generated high numbers of bands had higher MI and EMR values. Parameters such as MI and EMR have been used for assessing the informative potential of molecular markers in various genetic diversity studies [58,60].

Resolving power (RP): An important feature of a good marker system is the capacity to distinguish among different accessions. The resolving power (RP) is a parameter that specifies the discriminatory potential of the primers chosen.
Resolving power determines the ability of a primer/technique to generate optimally informative bands which were calculated per individual for each RAPD marker to determine their efficiencies. The estimates of RP varied from 4.8 to 20.0 with an average of 11.75 per primer. The highest RP values were recorded for the primers 3 (20.0), primer 2 (18.4), and primer 6 (13.2)) (Table 4), suggesting that (Rp) is an interesting tool to assess the capacity of a given these primers to distinguish among various genotypes. Since, these results revealed greater number of with total amplified bands was associated with the highest values of RP. While, the lowest value (4.8) was recorded for the primer7. It is the only primer out the eight primers was used, possessed four bands, indicating better resolving power of the RAPD markers. This is because of polyallelic nature of RAPD markers. However, the resolving power provides no information on the ability of a primer to reflect the genetic or taxonomic relationships of a group of genotypes under study [32]. There are many researches containing RP index investigation [59, 60, 64].

Confusion probability and Discrimination power: The confusion probability (C) is probability that two randomly chosen individuals from the sample of genotypes having identical banding patterns. While Discrimination power (DP) is an extension of the polymorphism information content [31] available from the frequencies of different banding patterns generated by a primer in different genotypes and represents the probability that two randomly chosen individuals have different patterns, and thus are distinguishable from one another. High values of discriminating capacity were obtained for the majority of the primers and its values ranged from 0.75 (primer 7) to 0.79 (Primer1, 2, 6, 8), with a mean value of 0.78 (Table 4 ). The high DP values indicate the lack of close genetic relatedness and better suitability to distinguish wheat genotypes. The high discriminating power of the RAPD primers examined in this study is coherent with that reported by Tessier et al. [31] and Besnard et al. [65] . However, in this study the discriminating capacity, negatively correlated to the confusion probability. Primer 7 showed highest $\mathrm{C}$ and low DP. The higher the confusion probability of a primer, the less suitable it is for fingerprinting [66].

Genetic similarity was calculated for five genotypes (data not shown). The similarities varied from 0.58 (genotype 3 vs. genotype 5) to 0.87 (genotype1 vs. genotype 2). Similar to findings by Sabbour et al. [67] found that the lowest similarity 0.58 was observed between Sakha93 and Gemmiza7. Moreover, the high value of genetic similarity between genotype 1 and genotype 2 could be as an indication that a large part of the genome of the genotypes under study is identical. This is primarily due to the lack of parental diversity, because of both genotypes may share somewhat similar parents in the pedigree.

Since, genetic similarity estimates are affected by a variety of factors some of which are important, like the distribution of markers in the genome (genome coverage) and the nature of evolutionary mechanisms underlying the variation measured [31]. High genetic similarity in the present analysis compared with published data of other authors [68-70], the 
explanation is might the lack of RAPD primer selection makes it difficult to make generalizations. Other primers may yield different results. Furthermore, the number of primers used was rather small. Thus, the number is probably too small for a reliable coverage of the genome, resulting in a distorted description of the genetic relationships. In addition to that, data computing errors like scoring non-homologous bands of similar mobility can influence the calculation of genetic distances.

A dendrogram based on UPGMA analysis with RAPD data (similarity matrix) was illustrated in Figure2. The five wheat genotypes were divided into two main clusters. Cluster 1 was dived into two groups. In sub group1 were included genotype 1 and genotype 2 . They seemed very close which might depict sharing of the genetic background among the genotypes. In consequence, the close genetic relationships are entirely alarming and may hinder further plant improvement. Genotype5 was in subgroup2. The second cluster was included genotype 3 and genotype 4 .

However, there were differences between genetic and phenotypic similarity in the studied genotypes. For example, the RAPD primers used showed that genotype1 and genotype 4 were genetically different from each other, but in the dendrogram created based on yield components, these genotypes were collected in one subgroup. A reasonable explanation for this apparent contradiction is that morphological traits are objectively selected for both, better agronomic performance and to get a combination of traits that allows variety identification and differentiation, which may be accomplished without dramatically changing the overall genetic background that is better described by the molecular markers. In other words, morphological traits are largely selectable markers as opposed to molecular markers that are mainly neutral to the selection process. While, RAPD loci were taken at random and tend to detect more structural changes. In addition to, morphological data matrix does not fully comply all the statistical assumptions for a reliable description, particularly those requiring independence of the variables. This confirms that morphological traits are not the best descriptors of the genetic evolution that conducted to the modern varieties.

Table 4. Molecular characteristics of 8 RAPD primers used to analyze five wheat genotypes.

\begin{tabular}{|c|c|c|c|c|c|c|c|c|c|c|c|c|}
\hline Primer & $\mathbf{N}$ & Polymorphic-N & \%polymorphism & $\mathrm{Ne}$ & PIC & $\mathbf{I}$ & SI & MI & EMR & RP & $\mathbf{C}$ & DP \\
\hline 1 & 8 & 4 & 50 & 7.52 & 0.87 & 2.04 & 0.89 & 0.44 & 0.50 & 12.80 & 0.21 & 0.79 \\
\hline 2 & 13 & 7 & 54 & 10.99 & 0.91 & 2.45 & 0.93 & 0.80 & 0.88 & 18.40 & 0.21 & 0.79 \\
\hline 3 & 18 & 14 & 78 & 14.29 & 0.93 & 2.77 & 0.95 & 1.63 & 1.76 & 20.00 & 0.23 & 0.77 \\
\hline 5 & 5 & 5 & 100 & 4.44 & 0.75 & 1.46 & 0.81 & 0.47 & 0.63 & 5.20 & 0.22 & 0.78 \\
\hline 6 & 12 & 10 & 83 & 9.26 & 0.89 & 2.33 & 0.92 & 1.11 & 1.25 & 13.20 & 0.21 & 0.79 \\
\hline 7 & 4 & 4 & 100 & 3.62 & 0.72 & 1.34 & 0.79 & 0.36 & 0.50 & 4.80 & 0.25 & 0.75 \\
\hline Total & 77 & 56 & & 63.52 & 6.77 & 16.38 & 7.06 & 6.09 & 7.02 & 94 & 1.79 & 6.21 \\
\hline Mean & 9.63 & 7 & & 7.94 & 0.85 & 2.05 & 0.88 & 0.76 & 0.88 & 11.75 & 0.22 & 0.78 \\
\hline
\end{tabular}

$* \mathrm{~N}=$ number of bands, $\mathrm{Ne}=$ effective number of alleles, Pic= Polymorphism information content, $\mathrm{I}=\mathrm{Shannon}$ index, $\mathrm{SI}=\mathrm{Sampson}$ index, $\mathrm{MI}=\mathrm{Marker} \mathrm{Index}$, $\mathrm{EMR}=$ Effective multiplex ratio, $\mathrm{RP}=$ Resolving power, $\mathrm{C}=$ Confusion probability, $\mathrm{DP}=\mathrm{Discrimination}$ power

Table 5. Variation present among the wheat genotypes in the number of bands of 8 RAPD primers.

\begin{tabular}{llllll}
\hline Genotypes & Sakha8 & Sakha69 & Sakha93 & Sids1 & Gemmiza7 \\
\hline primer & bands & bands & bands & bands & bands \\
\hline P1 & 8 & 8 & 5 & 4 & 7 \\
P2 & 10 & 7 & 6 & 5 & 10 \\
P3 & 10 & 14 & 6 & 5 & 15 \\
P4 & 5 & 3 & 3 & 2 & 8 \\
P5 & 3 & 2 & 2 & 2 & 4 \\
P6 & 8 & 8 & 5 & 5 & 7 \\
P7 & 1 & 1 & 4 & 3 & 3 \\
P8 & 6 & 7 & 3 & 6 & 3 \\
Total & 51 & 50 & 34 & 40 & 3 \\
\hline
\end{tabular}

\begin{tabular}{|c|c|c|c|c|c|}
\hline$C A S E$ & & $\begin{array}{ll}5 & 10\end{array}$ & 15 & 20 & \\
\hline Labe 1 & Num & +---------+---------+ & -+- & --+- & --+ \\
\hline G1 & 1 & & & & \\
\hline $\mathrm{G} 2$ & 2 & - & & & \\
\hline G5 & 5 & & & & \\
\hline G3 & 3 & & $\mathrm{~T}$ & & \\
\hline G4 & 4 & 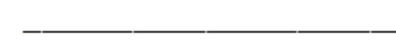 & 」 & & \\
\hline
\end{tabular}

Figure 2. Dendrogram for the five wheat genotypes constructed from RAPD data using (UPGMA). Genotype codes: see Table 1. 


\subsection{Wheat Genotypes Fingerprinting}

The higher number of unique bands was four in primers P3 and P6 while primer P2 gave only one band (Table 6). Primers $\mathrm{P} 1$ and $\mathrm{P} 7$ gave no unique band. The presence of such bands refers to that primer recognized a unique annealing site in genome, this increase chance of producing a unique cultivar fingerprint [71]. However, two possible reasons can be used to explain the presence of private alleles. First, mutations may occur in-situ and this suggests that the genotypes being studied have been present for more than one generation. Therefore, the existing plants are not founding individuals. Second, the lack of evidence of a recent bottleneck could suggest introductions from various source cultivars or earlier bottlenecks not detected as deviations from the mutation drift equilibrium. These undetected bottlenecks could be as a result of introduction by ancient humans [72].

The results obtained demonstrated that the RAPD approach have a considerable potential for identification and discrimination of different wheat cultivars. In additional to the specific or unique band derived from RAPD marker can be further developed as SCAR (sequence characterized amplified region) marker for rapid and simple identification of wheat cultivars. Such potentiality has also been highlighted by Belaj et al. [73], Rajora and Rahman [74] and Gorji et al. [75].

Table 6. Wheat genotypes fingerprinting (DNA profile) using eight RAPD primers.

\begin{tabular}{lllll}
\hline Primer & Number of unique bands & Size of the unique band (bp) & Genotypes -fingerprinting & Number of genotypes- fingerprinting \\
\hline P1 & - & - & - & - \\
P2 & 1 & 500 & Sids1 & 1 \\
P3 & 4 & $800,600,300$ & Gemmiza7 & 2 \\
P4 & 3 & 610 & Sakha69 & 1 \\
P5 & 2 & $900,650,610$ & Gemmiza7 & 2 \\
P6 & 4 & 250 & Sakha93 & Gemmiza7 \\
P7 & - & 180 & Gemmiza7 & 1 \\
P8 & 2 & $800,680,320,250$ & - & - \\
\hline
\end{tabular}

\section{Conclusion}

The use of RAPD analysis in the present study revealed an extensive amount of divergence leading to cultivar identification. The level of polymorphism observed was high (73\%), indicating a wide and diverse genetic based for genotypes used. According to PIC, RP, MI, DP values, RAPD primers seem to be the suitable technique for characterization the wheat varieties. The maximum genetic similarity (87\%) occurs in genotype 1 and genotype 2 while minimum genetic similarity $(58 \%)$ was found in genotype 3 and genotype 5 . The information about genetic similarity managed to shed more light on the genetic relatedness of wheat cultivars. This might assist breeders avoid any possibility of elite germplasm becoming genetically uniform and to set up the appropriate guidelines for successful breeding of wheat cultivars based on the established relationships. Efficiency and speed of plant breeding programs can be accelerated by marker assisted selection (MAS) and permit persistent progress in the advancement of selected material. The findings gathered here regarding to obtain DNA fingerprints as specific or unique bands that derived from RAPD marker can be further developed as SCAR (sequence characterized amplified region) marker in order to establish the molecular identify of wheat cultivars. In addition to the characterizations based on the agronomic values could be useful in case when it necessary to obtain an agronomic description of the germplasms used. The mapped molecular markers closely associated to agronomic value (both single and quantitative trait loci) can provide the best solution for characterizations studies. Finally, the information resulted from this study can be used to contribute in putting the core stone of the data base for Egyptian wheat varieties to be used in the future as an indicator for breeding programs.

\section{References}

[1] FAO (2015). Production and protection series http: www.fao.org/worldfoodsituation/csdb.

[2] Rosegrant A. L. (1997). Wheat Demand in Future", Oxford Economic Papers, Vol. 28, pp. 102-117.

[3] Briggle, L. W. \& Reitz, L. P. (1963). Classification of Triticumspecies and of wheat varieties grown in the United States. Technical Bulletin 1278. United States Department of Agriculture.

[4] Joshi, C. P., and Nguyen, H. T. (1993). RAPD (random amplied polymorphic DNA) analysis based intervarietal genetic relationships among hexaploid wheat. Plant Science. 93: 95-103.

[5] The Agricultural Economics and Statistics Department, Ministry of Agriculture, Egypt (2014).

[6] Bretting PK \&Widrlechner MP (1995). Genetic markers and plant genetic resources management. In: Plant breeding reviews (Janick J, ed.). John Wiley and Sons Inc., New York, 11-87.

[7] Heckenberger, M., Maurer, H. P., Melchinger, A. E., \& Frisch, M. (2008). The lab soft database: A comprehensive database management system for intergrating phenotypic and genomic data in academic and commercial plant breeding programs. Euphytica, 161, 173-179. 
[8] Adugna, W., Labuschagne, M. T., \&Viljoen, C. D. (2006). The use of morphological and AFLP markers in diversity analysis of linseed. Biodiversity and Conservation, 15, 3193-3205.

[9] Sultana, T., Ghafoor, A., \& Ashraf, M. (2005). Genetic divergence in lentil germplasm for botanical descriptors in relation with geographic origins. Pakistan Journal of Botany, 37, 61-69.

[10] Fufa, H., Baenziger, P. S., Beecher, B. S., Dweikat, I., Graybosch, R. A., and Eskridge, K. M. (2005). Comparison of phenotypic and molecular marker-based classifications of hard red winter wheat cultivars. Euphytica, 145, 133-146.

[11] Manifesto, M. M., Schlatter, A. S., Hopp, H. E., Suarez, E. Y., Dubcovky, J., (2001). Quantitative evaluation of genetic diversity germplasm using molecular markers. Crop Science. 41, 682-690.

[12] Stuber CW, Edwards MD, Wendal JF (1987) Molecular marker Facilite'd investigations of quantitative traits loci in maize 2. Factors influencing yield and its component traits. Crop Science. 27, 639-648.

[13] O"zlem Ates, So"nmezog, Begu“m Terzi. (2018). Characterization of some bread wheat genotypes using molecular markers for drought tolerance. Physiology and Molecular Biology of Plants .24: 159-166.

[14] Piyusha S\& Naveen K S. (2018). SSR Molecular Markers are efficient tools for finding Genetic Diversity in Bread Wheat. International Journal of Current Microbiology and Applied Sciences .1098-1105.

[15] Tanksley SD, Young ND, Paterson AH, Bonierbale MW (1989) RFLP mapping in plant breeding: new tools for an old science. Biotechnology 7, 257-264.

[16] Paterson AH, Damon S, Hewitt JD, Zamir D, Rabinowitch HD, Lincoln SE, Lander ES, Tanksley SD (1991) Mendelian factors underlying quantitative traits in tomato: comparison across species, generations and environments. Genetics 127, 181-197.

[17] Ashraf, J.; Malik, W.; Iqbal, M.; Khan, A.; Qayyum, A.; Noor, E.; Abid, M.; Cheema, H.; Ahmad, M. (2016) Comparative analysis of genetic diversity among bt cotton genotypes using est-ssr, issr and morphological markers. J. Agric. Sci. Technol., 18, 517-531.

[18] Kara, K. and M. R. Knaouni (2017). Genetic diversity of bread wheat genotypes revealed by revealed by agromorphological characteristics and microsatellite SSR markers. International Journal of Engineering Research and Technology.6: 176-182.

[19] Phougat D, I. S. Panwar, M. S. Punia and S. K. Sethi. (2018). Microsatellite markers-based characterization in advance breeding lines and cultivars of bread wheat. Journal of Environmental Biology.39: 339-346.

[20] Williams, J. G., Kubelik, A. R., Livak, K. J., Rafalski, J. A., and Tingey, S. V. (1990). DNA polymorphisms amplified by arbitrary primers are useful as genetic markers. Nucleic Acids. Research, 18, 6531-6535.

[21] Ovesna, J., Polakova, K., and Leisova, L. (2002). DNA analyses and their application in plant breeding. Czech Journal of Genetics and Plant Breeding, 38, 29-40.

[22] Kumar, P., Gupta, V. K., Misra, A. K., Modi, D. R., and
Pandey, B. K. (2009). Potential of molecular markers in plant biotechnology. Plant Omics Journal, 2, 141-162.

[23] Asif, M., Rahman, M., and Zafar, Y. (2005). DNA fingerprint studies of some wheat (Triticum aestivum L.) genotypes using random amplified polymorphic (RAPD) analysis. Pakistan Journal of Botany, 37, 271-277.

[24] Nimbal, S., R. K. Behl and A. K. Chhabra, (2009). RAPD analysis for genetic polymorphism in bread wheat (Triticum aestivum L. em. Thell) genotypes varying for grain protein content. The South Pacific Journal of Natural Science, 27: 4956 .

[25] Saleh, B., (2012). Biochemical and Genetic Variation of some Syrian Wheat Varieties using NIR, RAPD and AFLPs Techniques. Journal of Plant Biology Research, 1 (1): 1-11.

[26] SAS Institute (2003) SAS Users Guide. Version 9.1 reviews. SAS Institute INS Inc, Cary, NC.

[27] Dellaporta, S. L., Wood, J., Hicks, J. B. (1983) A plant DNA minipreparation: Version II. Plant Molecular Biology Reporter, 1 (4). pp. 19-21. ISSN 07359640 (ISSN).

[28] Porebski, S., Bailey, L. G. and Baum, B. R. (1997) Modification of a CTAB DNA Extraction Protocol for Plants Containing High Polysaccharide and Polyphenol Components. Plant Molecular Biology Reporter, 15, 8-15.

[29] Liu K \& Muse SV. (2005). Power Marker: an integrated analysis environment for genetic marker analysis. Bioinformatics. 21: 2128-2129.

[30] Shannon, C. E. \& Weaver, W. (1949). The mathematical theory of communication. University of Illinois Press, Urbana, USA.

[31] Powell W, Morgante M, Andre C, Hanafey M, Vogel J, Tingey S, Rafalski A. (1996) The comparison of RFLP, RAPD, AFLP and SSR (Microsatellite) markers for germplasm analysis. Molecular Breeding. 2,225-238.

[32] Prevost, A. \& Wilkinson, M. J. (1999) A New System of Comparing PCR Primers Applied to ISSR Fingerprinting of Potato Cultivars. Theoretical and Applied Genetics, 98, 107-112.

[33] Tessier, R., J. David, P. This, J. M. Boursiquot, and A. Charrier. (1999). Optimization of the choice of molecular markers for varietal identification in Vitis vinifera L. Theoretical and Applied Genetics .98: 171-177.

[34] Smith, J. S. C \&Smith O. S. (1992): Fingerprinting crop varieties. Advances in Agronomy. 47: 85-140.

[35] Salem KFM, El-Zanaty AM, Esmail RM (2008) Assessing wheat (Triticum Aestivum L.) genetic diversity using morphological characters and microsatellite markers. World Journal of Agricultural Sciences 4: 538-544.

[36] Pagnotta MA, Mondini L, Codianni P, Fares C (2009). Agronomical, quality, and molecular characterization of twenty Italian emmer wheat (Triticum dicoccon) accessions. Genetic Resources and Crop Evolution 56: 299-310.

[37] Zarkti H, Ouabbou H, Hilali A, Udupa SM (2010). Detection of genetic diversity in Moroccan durum wheat accessions using agro-morphological traits and microsatellite markers. African journal of agricultural research, 5: 1837-1844.

[38] Ahmed NCM \&Khaliq IMM (2007). The inheritance of yield and yield components of five wheat hybrid populations under drought conditions. Indonesian J. Agric. Sci., 8 (2): 53-59. 
[39] Songsri P, Joglloy S, Kesmala T, Vorasoot N, Akkasaeng CPA, Holbrook C (2008). Heritability of drought resistance traits and correlation of drought resistance and agronomic traits in peanut. Crop Science., 48: 2245-2253.

[40] Abou-Deif. M. H, M. A. Rashed, M. A. A. Sallam, E. A. H. Mostafa and W. A. Ramadan. (2015). Response of Twenty Wheat Varieties to Drought Stress Based on Some Agronomic Traits and Molecular Analysis. Asian Journal of Plant Sciences 14 (1): 1-10.

[41] Snape JW, Butterworth K, Whitechurch E, Worland AJ. (2001). Waiting for fine times: genetics of flowering time in wheat. Euphytica. ; 119: 185-90.

[42] Seki M, Chono M, Matsunaka H, Fujita M, Oda S, Kubo K (2011). Distribution of photoperiod-insensitive alleles Ppd-B1a and Ppd-D1a and their effect on heading time in Japanese wheat cultivars. Breed Sci.; 61: 405-12.

[43] Abdelsalam N R \& Reham MA (2013). Genetic diversity of domesticated wheat and wild wheat. Egypt. J. Genet. Cytol., 42: 21-36.

[44] Al-Naggar AM, Sobieh ES, Atta MM \& Al-Azab KF (2013). Unique SSR markers for drought tolerance in newly-developed bread wheat. World Research Journal of Agronomy. 1.-015-025.

[45] Kiseleva Antonina A., Andrey B. Shcherban, Irina N. Leonova, Zeev Frenkel and Elena A. Salina. (2016.) Identification of new heading date determinants in wheat $5 \mathrm{~B}$ chromosome. BMC Plant Biology.35-81.

[46] Ahmadizadeh M., Shahbazi H., Valizadeh M., Zaefizadeh M. (2011). Genetic diversity of durum wheat landraces using multivariate analysis under normal irrigation and drought stress conditions. Afr. J. Agric. Res. 6: 2294-2302.

[47] Talebi R., Fayyaz F. (2012). Quantitative evaluation of genetic diversity in Iranian modern cultivars of wheat (Triticum aestivum L.) using morphological and amplified fragment length polymorphism (AFLP) markers. Biharean Biologist, 6: 14-18.

[48] Shashikala S. K. (2006). Analysis of genetic diversity in wheat. MSc. University of Agricultural Sciences, Dharwad.

[49] Nimbalkar, C. A., NavaleP. A.\& Biradar, A. B. (2002). genetic diversity in wheat. Journal of Maharashtra Agricultural Universities, 27 (1): 43-45.

[50] Moioli, B., A. Georgoudis, F. Napolitano, G. Catillo, E. Giubilei, C. Ligda and M. Hassanane. (2001). Genetic Diversity between Italian, Greek and Egyptian buffalo populations. Livestock Production Science. 70: 203-211.

[51] Ramiz T A, Mehraj A. \& Alamdar C M. (2007). Genetic Identification of Diploid and Tetraploid Wheat Species with RAPD Markers. Turk J Biol 31: 173-180.

[52] Qadir S A, Mohammed Q. K,\&Fahrul Z H. (2017). Drought Tolerance and Genetic Diversity among Selected Wheat Cultivars ZANCO Journal of Pure and Applied Sciences. 29 (3): 110-117.

[53] Ajibade, S., Weeden, N. \& Chite, S. (2000). Inter simple sequence repeat analysis of genetic relations in genus Vigna. Euphytica. 111: 47-55.

[54] Ghalmi, N., Malice. M., Ounan, S and Baudoin, J. (2010). Morphological and molecular diversity within Algerian Cowpea (Vigna Unguiculata L) landraces. Genetic Resources and Crop
Evolution 57: 371-386.

[55] Hurtado, A., \& Rodríguez-Valera, F. (1999). Accessory DNA in the genomes of representatives of the Escherichia coli reference collection. Journal of bacteriology, 181 (8), 2548-2554.

[56] Crespan, M R. Botta, N. Milani, (1999) Molecular characterization of twenty seeded and seedless table grape cultivars grape (Vitisvinifera L.), Vitis. 38: 87-92.

[57] Novoselovi'c D, Bentley AR, Šimek R, Dvojkovi' cK, Sorrells ME, Gosman N, Horsnell R, Drezner G and Šatovi' cZ (2016) Characterizing Croatian Wheat Germplasm Diversity and Structure in a European Context by DArT Markers. Front. Plant Sci. 7: 184. doi: 10.3389/fpls.2016.00184.

[58] Najaphy A., R. Ashrafi Parchin, and E. Farshadfar (2011). Evaluation of genetic diversity in wheat cultivars and breeding lines using inter simple sequence repeat markers. Biotechnology \& Biotechnological Equipment. 4: 2634-2638.

[59] Dalamu T., K. Behera, A. B. Gaikwad, S. Saxena, C. Bharadwaj, and A. D. Munshi (2012). Morphological and molecular analyses define the genetic diversity of Asian bitter gourd (Momordica charantia L.). Australian Journal of Crop Science 6: 261 .

[60] Sadeghi A. and K. Cheghamirza (2012). Efficiency of RAPD and ISSR marker systems for studying genetic diversity in common bean (Phaseolus vulgaris L.) cultivars. Annals of Biological Research. 3: 3267-3273.

[61] Safari S., A. A. Mehrabi, and Z. Safari (2013). Efficiency of RAPD and ISSR markers in assessment of genetic diversity in Brassica napus genotypes. International Journal of Agriculture and Crop Sciences 5: 273-279.

[62] Botstein, D., R. L. White, M. Skolnick and R. W. Davis. (1980). Construction of a genetic linkage map in man using restriction fragment length polymorphism. The American Journal of Human Genetics. 32: 314- 331.

[63] Bibi S, Imtiaz A., Khan M., Abdullah K \&Nighat S. (2012). Estimation of genetic variability among elite wheat genotypes using RAPD analysis. Pak. J. Bot., 44 (6): 2033-2040.

[64] Al-Kaab, Dhafir H.; Hamdalla, Majid Sh.; Dweikat, Ismail M.; and Al-Saedi, Noora J., (2016). "Estimation of the Degree of Diversity for SomeIraqi Wheat Varieties through ISSR, SRAP and RAPD Markers. American Journal of Experimental Agriculture .11 (3): 1-11.

[65] Besnard, G., Breton, C., Baradat, P., Khadari, B. and Bervillé, A.(2001). Cultivar identification in olive based on RAPD markers. J. Am. Soc. Hort. Sci. 126: 668-675.

[66] Nagaich D \& A Chandra. (2009). Assessment of Genetic Diversity and Identification of Informative Molecular Markers for Germplasm Characterization in CaribbeanStylo (Stylosanthes hamata). J. Plant Biochemistry \& Biotechnology Vol. 18 (2), 257-260,

[67] Sabbour, A. M. Elham F. Gomaa, 2R. A. Sallam and Shimaa A. Shaaban. (2015). Genetic Diversity among Some Wheat (Triticum aestivum L.) Genotypes as Revealed by RAPD and SSR Analyses. American-Eurasian J. Agric. \& Environ. Sci., 15 (10): 2069-2075

[68] ALiYEV R, Mehraj A, Alamdar C. (2007). Genetic Identification of Diploid and Tetraploid Wheat Species with RAPD Markers. Turkish Journal of Biology 31: 173-180. 
[69] Al-Doss. A, Khaled. A, Eid. A and Mohamed, B. (2009). Assessment of genetic diversity in Saudi wheat genotypes under heat stress using molecular markers and agronomic traits. International journal of plant breeding. 3 (20): 103-110.

[70] Olgun M., Gözde A, Metin T, Onur K and Engin T. (2015). Identification of Genetic Divergence in Some Bread Wheat Varieties by Rapd and Issr Analyses. Süleyman Demirel Üniversitesi Ziraat Fakültesi Dergisi 10 (2): 94-101.

[71] AL-Tamimi, A. J. T. (2014). Genetic Diversity of Some Tomato Genotypes Using RAPD and SSR markers in Iraq. PhD thesis. Faculty of science. University of kufa. p 183.

[72] Bell, K. L., Rangan, H., Kull, C. A., Murphy, D. J., Botanic, R., \& Victoria, G. (2015). The history of introduction of the African baobab Malvaceae : Bombacoideae ) in the Indian subcontinent.: Royal Society Open science. 2: 150370. http://dx.doi.org/10.1098/rsos.150370.
[73] Belaj, A.; Satovic, Z.; Cipriani, G.; Baldoni, L.; Testolin, L.; Rallo, L. (2003). Comparative study of the discriminating capacity of RAPD, AFLP and SSR markers and of their effectiveness in establishing genetic relationships in olive. Theoretical and Applied Genetics. 107: 736.

[74] Rajora, O. and Rahman, M. (2003). Microsatellite DNA and RAPD fingerprinting, identification and genetic relationships of hybrid poplar (Populus $x$ canadensis) cultivars. Theoretical and Applied Genetics. 106: 470-477.

[75] Gorji, A. H.; Darvish, F.; Esmaeil zadehadam, M. and Aziz F. (2010). Application RAPD technique for recognition genotypes tolerant to drought in some of bread wheat. Asian Journal of Biotechnology.2 (3): 159-168. 